\title{
Investigation into the effect of season on oestrus in gilts over two years of climate adaptation
}

\author{
N. Dojana\#, G. Cotor, I. Codreanu, S. Raita, R. A. Balaceanu \& C. Budica \\ Faculty of Veterinary Medicine, University of Agronomical Science and Veterinary Medicine of Bucharest, 105 Splaiu \\ Independentei Str., 050097 Bucharest, Romania
}

(Received 17 June 2016; Accepted 6 February2017; First published online 13 February 2017)

\author{
Copyright resides with the authors in terms of the Creative Commons Attribution 4.0 South African License. \\ See: http://creativecommons.org/licenses/by/4.0/za \\ Condition of use: The user may copy, distribute, transmit and adapt the work, but must recognize the authors and the South African \\ Journal of Animal Science.
}

\begin{abstract}
This study examined the changes in age at first oestrus, the weaning-to-oestrus interval (WEI), and duration of oestrus (DE) in a Yorkshire sow population during two years of adaptation from a northern $\left(55^{\circ} 48^{\prime} \mathrm{N}, 9^{\circ} 13^{\prime} \mathrm{W}\right)$ European region to a southern $\left(44^{\circ} 03^{\prime} \mathrm{N}, 23^{\circ} 35^{\prime} \mathrm{W}\right)$ one. The adaptation process induced a grouping effect of gilts around the mean age of the onset of puberty. Autumn and spring were characterized by the most enhanced gilt grouping effect at 201 to 210 days of age. The same effect was found for oestrus duration, which declined from a 12- to 96-hour range in the first year to an 18- to 90-hour range in the second year. The mean age of first oestrus was 0.8 days significantly lower in the second year compared with the first; the maximal lowering (1.7 days) occurred in the winter season. The WEI decreased significantly from the first to the second year in all four seasons, by a mean annual value of 0.88 days $(15.9 \%)$. DE increased by 6.5 hours (significantly for all seasons) from the first year to the next. DE showed an ascending evolution from winter to spring and descending from summer to autumn, during each monitored year. Adaptation influences the oestrus in sows. The age to puberty and WEI tended to decrease, while DE tended to increase, with a simultaneous decrease in the variability of these oestrus parameters.
\end{abstract}

Keywords: Age of puberty, climate conditions, length of oestrus, weaning to oestrus interval

\# Corresponding author: nicolaedojana@fmvb.ro

\section{Introduction}

Translocation of pigs between climatic regions has an effect on the physiological status of the animals through exposure to stressors (Bernabucci et al., 2010). Translocated animals need an adaptation period to acclimatize to these new conditions. Adaptation involves phenotypic and genetic changes that reduce the physiological trauma produced by stressful components (e.g. temperature and photoperiodicity) of the total (natural and controlled) environment (Bernabucci et al., 2010).

Adaptation takes place continuously over the lifetime of an animal or over several generations, whereas seasonality has a well-known but complex effect on the reproductive physiology of the pig (Peltoniemi et al., 2000; Gourdine et al., 2006). The seasonal effects on the reproductive performance of domestic sows were described many years ago, with a period of infertility during summer and early autumn (Hutchens et al., 1978; Hurtgen et al., 1980; Somade \& Makinde, 1985). This incorporates common manifestations of decreased reproductive parameters, including delayed puberty in gilts, prolonged WEI, lower farrowing rate, and reduced litter size (Tummaruk et al., 2004; Chokoe \& Siebrits, 2009). These influences are induced primarily by photoperiod and climatic variations, especially temperature.

Aside from environmental factors, hormonal (e.g. melatonin profile) and genetic factors are important elements in seasonal variations of reproductive parameters in sows (Gourdine et al., 2006; Chokoe \& Siebrits, 2009). Knox \& Zas (2001) and Knox et al. (2002) reported that seasonal photoperiodicity is related to length of lactation, frequency of exposure to boar, housing, feed, light conditions, and group size. The underlying mechanism of this relationship probably involves melatonin secretion (Quesnel et al., 2005; Gourdine et al., 2006).

Achieving a rapid modification of photoperiodicity by transferring animals between geographic regions with different photoperiods and temperatures may contribute to better understanding of the ability of the sow to adapt to climate changes. Therefore, this study investigated certain selected reproduction parameters, including age at puberty, WEI, and DE of sows that were moved from a northern EU climate region to a southern one. The goal was to improve understanding of how sows adapt to climate change. 


\section{Material and methods}

Research was conducted with a Yorkshire $(Y)$ gilt population mated with Landrace boars. These $Y$ gilts were moved in four groups from a pig farm in Denmark $\left(55^{\circ} 48^{\prime} \mathrm{N}, 9^{\circ} 13^{\prime} \mathrm{W}\right)$ to a commercial pig farm in south Romania $\left(44^{\circ} 03^{\prime} \mathrm{N}, 23^{\circ} 35^{\prime} \mathrm{W}\right)$, followed by a seven-week period of acclimatization. Ages varied from 16 weeks to 30 weeks at the moment of translocation. Local climate particularities in south Romania are presented in Table 1.

Table 1 Main local climate data summarized from data collected from September 2013 to September 2015*

\begin{tabular}{|c|c|c|c|c|c|c|c|}
\hline \multirow[t]{2}{*}{ Season } & \multicolumn{2}{|c|}{$\begin{array}{l}\text { Mean ( } \pm \text { SD) daily } \\
\text { sunshine (hours) }\end{array}$} & \multicolumn{2}{|c|}{$\begin{array}{c}\text { Mean }( \pm S D) \text { maximum } \\
\text { external local } \\
\text { temperatures } \\
\text { (degrees Celsius) } \\
\end{array}$} & \multicolumn{2}{|c|}{$\begin{array}{c}\text { Mean }( \pm S D) \text { minimum } \\
\text { external local } \\
\text { temperatures } \\
\text { (degrees Celsius) } \\
\end{array}$} & \multirow[t]{2}{*}{$\begin{array}{l}\text { Photophase } \\
\text { (hours: } \\
\text { minutes) }\end{array}$} \\
\hline & First year & Second year & First year & Second year & First year & Second year & \\
\hline Autumn & $3.33 \pm 0.44$ & $3.30 \pm 0.52$ & $+13.93 \pm 3.51$ & $+13.32 \pm 1.03$ & $+1.6 \pm 0.24$ & $+1.4 \pm 0.09$ & 9:26 \\
\hline Winter & $3.33 \pm 0.32$ & $3.36 \pm 0.65$ & $+5.30 \pm 0.76$ & $+5.37 \pm 1.07$ & $-3.50 \pm 0.22$ & $-3.53 \pm 0.60$ & $10: 43$ \\
\hline Spring & $7.63 \pm 1.30$ & $7.86 \pm 1.14$ & $+22.70 \pm 4.44$ & $+23.05 \pm 3.03$ & $+10.0 \pm 2.01$ & $+10.1 \pm 2.09$ & $14: 58$ \\
\hline Summer & $9.61 \pm 1.22$ & $9.96 \pm 0.51$ & $+27.20 \pm 6.62$ & $+28.11 \pm 4.76$ & $+13.9 \pm 3.90$ & $+14.4 \pm 3.13$ & $13: 48$ \\
\hline
\end{tabular}

* Data were provided by Administrația Națională de Meteorologie in Romania

The pig farm in Romania practises a weekly breeding system, in which $Y$ gilts are artificially inseminated with Landrace sperm. The gilts are mated at 31 to 33 weeks of age. Pregnancy is confirmed 25 to 28 days after mating and reconfirmed 42 days later. Pregnant gilts are transferred to individual free-access pens. On the last Friday of gestation, pregnant gilts are transferred to individual maternity pens. Parturition is synchronized on the last Thursday morning at 08:00 using $0.7 \mathrm{~mL}$ of cloprostenol injected intramuscularly after which farrowing starts within $24 \pm 5$ hours. Farrowing takes place from Thursday evening until Sunday, and animals are maintained in this grouping. Piglets are weaned at 25 to 27 days of age (on the last Thursday). Sows are separated from weaned piglets and housed individually, being mated at oestrus.

Animals were housed under natural light conditions in $10.4 \mathrm{~m} \times 30.7 \mathrm{~m}$ pens equipped with a ventilation system and underfloor heating. Light intensity ranged between 51 and $64 \mathrm{Im} / \mathrm{m}^{2}$.

A total of $697 \mathrm{Y}$ gilts were monitored to determine the age to first oestrus by daily observation for vulval reddening and swelling, and testing the response to back pressure in the presence (nose-to-nose contact) of a mature boar for 5 to 10 minutes at approximately 08:00, 14:00, and 20:00 hours local time $(+2$ Greenwich Mean Time). For this study, puberty was defined as the age at which oestrus was first detectable. The duration of first oestrus was measured on the same gilts, and was defined as the time from the first positive back pressure of the testing response until the test was negative (hours).

The same animals, as parity-1 sows, were monitored for WEI, which was measured as the time from weaning to the time of first detected oestrus (days). Monitoring occurred during the first and the second years of adaptation, from 22 September 2013 to 21 September 2015. Each year was divided into the four commonly recognized seasons in the north temperate zone, namely autumn, winter, spring, and summer.

Gilts were assigned to eight groups of 10-day intervals, based on their age at the first observed oestrus: 161 to 170 days, 171 to 180 days, 181 to 190 days until 231 to 240 days, with 191 to 210 days considered a normal puberty interval (NPI) (Anderson, 1993). Gilts monitored for DE were included in groups of six-hour intervals from 6 to 102 hours. A 48- to 72-hour interval was considered the normal range of DE (Anderson, 1993).

Data were analysed with the analysis of variance (ANOVA) general linear model procedure of SAS (2002). The season and year of monitoring were independent variables. Dependent variables included age of first oestrus, WEI, and DE. The values for each dependent variable were determined separately; therefore, three sets of analyses were performed. The calculated descriptive statistics that were utilized were the mean and standard deviation. The statistical significance of the data in each year was analysed using single-factor ANOVA. When the null hypothesis was rejected within the same year of monitoring, Tukey's post-hoc test was performed to determine the season(s) with statistically significant difference. Seasons were compared between the first and second years of adaptation using a single factor ANOVA. The significance level of null hypothesis rejection was $P<0.05$. 


\section{Results}

The percentage of gilts reaching oestrus within the limits of NPI was $43.4 \%$ (autumn), $44.6 \%$ (winter), $36.0 \%$ (spring), and $43.0 \%$ (summer), in the first year of adaptation (Figure 1). An increase was found in the next year: $56.5 \%, 48.9 \%, 54.3 \%$ and $44.0 \%$, respectively. A total of 141 gilts ( $41.7 \%$ of those monitored) reached oestrus in NPI in the first year of adaptation, while 183 gilts $(50.9 \%$ of those monitored) reached oestrus within the same NPI limits during the second year. No seasonal differences of NPI were observed in the first year $(P=0.096)$; however, seasonal differences in the second year were very significant.
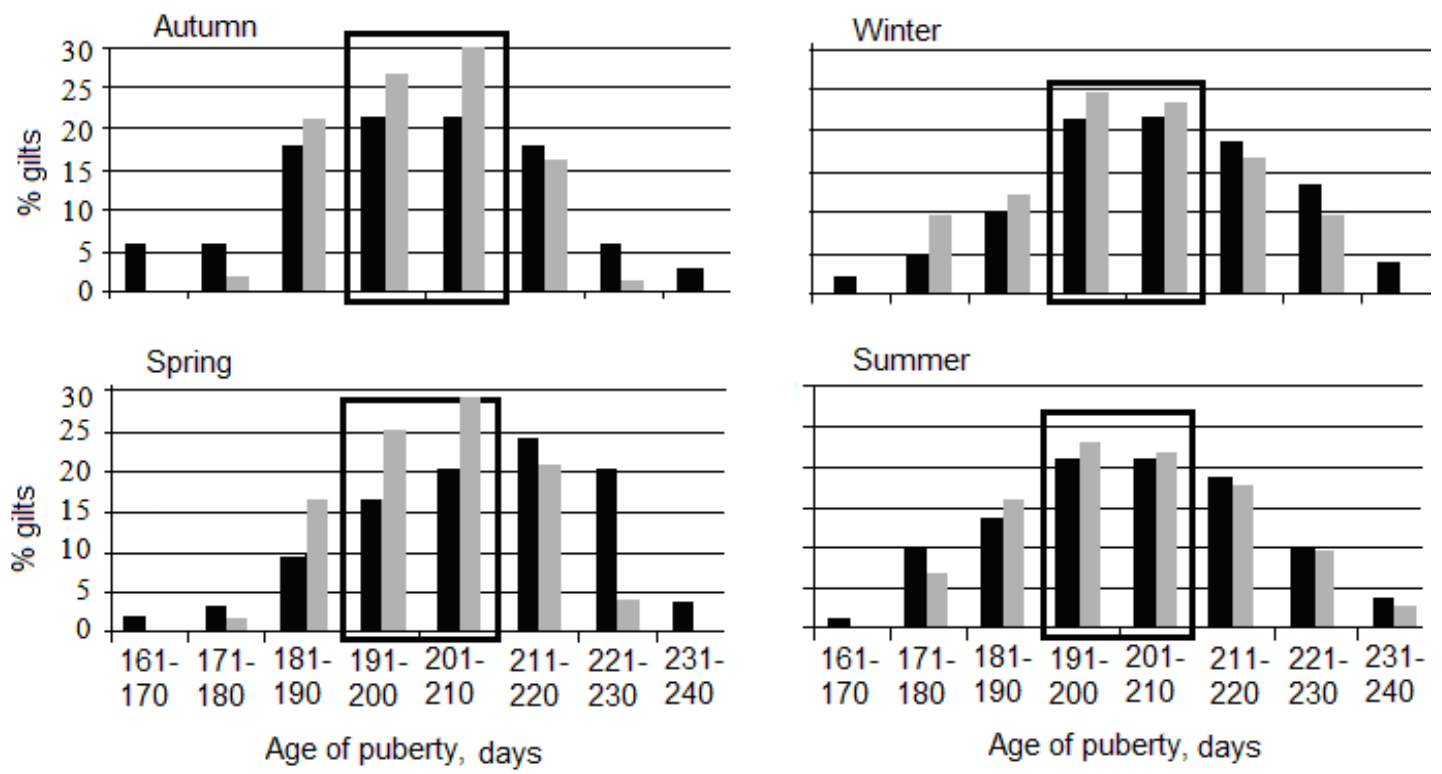

- First year $\quad$ Second year

Figure 1 Comparative seasonal repartition of gilts based on age at puberty during two years of climate adaptation

Each data point represents the percentage of gilts that reached oestrus compared with the total number monitored in that season. Intervals delimited by the thick rectangles are considered normal puberty intervals.

The mean age at the onset of puberty was lower in winter than in autumn $(P=0.011)$, spring $(P$ $=0.002$ ), and summer $(P=0.040)$ in the first year of adaptation (Table 2$)$. The onset of puberty was again lower in winter than in autumn, spring, and summer in the second year $(P=0.009,0.030$, and 0.029 , respectively). The seasonal decrease in age at the onset of puberty from the first to second year was not high $(P>0.05)$ except in winter $(P=0.003)$. A combined analysis of differences between the mean age to the onset of puberty in the first and second years show differences $(P=0.022)$.

Table 2 Age to first oestrus (days) in gilts ${ }^{1}$ during the seasons of two consecutive years of climate adaptation

\begin{tabular}{|c|c|c|c|c|c|c|c|}
\hline \multirow{2}{*}{ Item } & \multicolumn{4}{|c|}{ Season $^{2,3}$} & \multirow{2}{*}{ Annual $^{3}$} & \multirow{2}{*}{ SD } & \multirow{2}{*}{$P$} \\
\hline & Autumn & Winter & Spring & Summer & & & \\
\hline First year & $203.2^{\mathrm{b}} \pm 4.2$ & $200.1^{\mathrm{a} ; \mathrm{t}} \pm 3.6$ & $204.4^{C} \pm 2.5$ & $206.5^{d} \pm 2.7$ & $203.5 \pm 2.4$ & 8.88 & 0.037 \\
\hline Second year & $202.6^{b} \pm 3.8$ & $198.4^{\mathrm{a} ; \mathrm{a}} \pm 4.0$ & $204.0^{c} \pm 3.8$ & $206.1^{d} \pm 2.8$ & $202.7 \pm 2.1$ & 4.41 & $<0.001$ \\
\hline
\end{tabular}

\footnotetext{
'Provided by a Yorkshire population mated with Landrace boars during the first and the second year of adaptation from a northern to a southern EU region

${ }^{2}$ Seasons were classified as autumn (September equinox to December solstice), winter (December solstice to March equinox), spring (March equinox to June solstice) and summer (June solstice to September equinox)

${ }^{3}$ Values are expressed as mean \pm SEM

${ }_{a-d}$ Row means with different superscripts differ significantly at $P<0.05$

t; Column means with different symbols differ significantly at $P<0.05$
} 
The percentages of gilts that showed DE in normal limits in their first year of life in the new climate versus the second year were as follows: $47.6 \%$ vs. $63.5 \%$ in autumn, $42.0 \%$ vs. $60.5 \%$ in winter, $48.6 \%$ vs. $72.4 \%$ in spring and $41.7 \%$ vs. $61.3 \%$ in summer $(P<0.001$; Figure 2). However, the percentage of gilts with extreme values (minimal or maximal) for DE decreased from the first year to the next compared with a median value, and their distribution approached a Gaussian distribution. These effects were expressed strongly in autumn and spring.
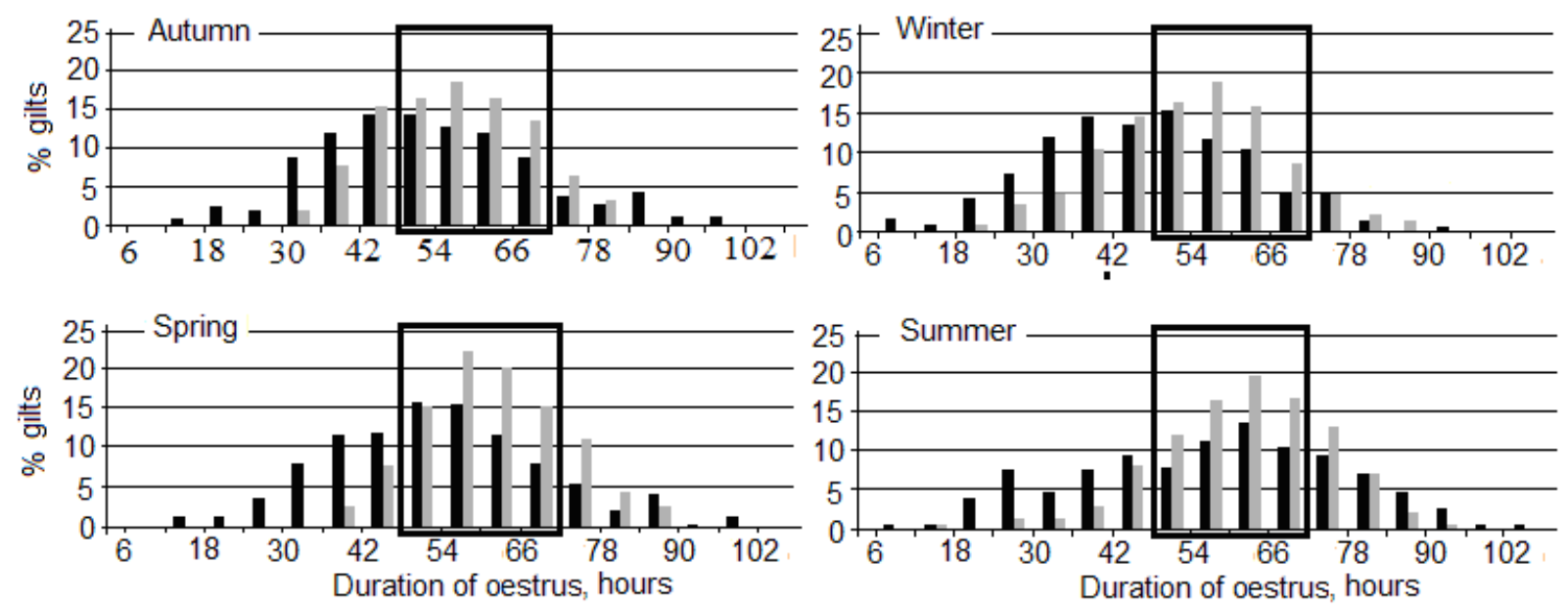

- First year

- Second year

Figure 2 Comparative seasonal repartition of gilts, based on the length of oestrus, from 6 to 102 hours, during two years of climate adaptation

Each data point represents the calculated percentage of the gilts that reached oestrus compared with the total number of gilts monitored in that season. Intervals delimited by the thick rectangles (48-72 hours) are considered as normal duration of oestrus. Note the two or three peaks of the values for the first year of adaptation

The DE in the first year was lower in autumn than in spring $(P=0.021)$ and summer $(P=0.019$; Table 3). Overall, DE increased by 6.55 hours from the first to the second year of adaptation $(P=0.009)$. The increases were different for each season $(P=0.003$ in autumn, $P=0.002$ in winter, $P=0.005$ in spring, and $P$ $=0.004$ in summer). Significant inter-seasonal differences were also detected during the second year.

The DE showed an upward trend during the winter-spring period $(+7.5$ hours), followed by a downward trend in the summer to autumn period ( -5.5 hours) in the first year. The trend was similar for the second year, but with lower maximum values $(+5.9$ hours and -3.3 hours, respectively). Likewise, the increase in DE from year to year was highest in autumn (9.1 hours) and lowest in spring (4.3 hours). Movement of the frequency distribution of $D E$ from the left toward the right follows the same general trend of adaptation to the new climatic conditions.

Table 3 Oestrus length (hours) during different seasons in gilts during two consecutive years of climate adaptation

\begin{tabular}{|c|c|c|c|c|c|c|c|}
\hline \multirow{2}{*}{ Item } & \multicolumn{4}{|c|}{ Season $^{1}$} & \multirow{2}{*}{ Annual $^{1}$} & \multirow{2}{*}{ SD } & \multirow{2}{*}{$P$} \\
\hline & Autumn & Winter & Spring & Summer & & & \\
\hline First year of adaptation & $47.1^{\mathrm{a} ; \dagger} \pm 2.6$ & $48.4^{\dagger} \pm 3.3$ & $55.9^{\mathrm{b} ; \dagger} \pm 2.5$ & $52.6^{c ; \dagger} \pm 2.2$ & $51.00 \pm 2.4$ & 11.0 & 0.066 \\
\hline Second year of adaptation & $56.2^{\ddagger} \pm 2.4$ & $54.3^{\mathrm{a} ; \ddagger} \pm 2.7$ & $60.2^{\mathrm{b} ; \ddagger} \pm 2.0$ & $59.5^{c ; \ddagger} \pm 1.9$ & $57.55 \pm 1.9$ & 9.4 & 0.002 \\
\hline
\end{tabular}

\footnotetext{
${ }^{1}$ Values are expressed as mean \pm SEM

${ }^{a-c}$ Row means with different superscripts differ significantly at $P<0.05$

t; $\ddagger$ Column means with different symbols differ significantly at $P<0.05$
} 
The shortest WEI occurred in the winter, which was lower than in autumn $(P=0.037)$ and in summer $(P=0.010)$ during the first year of monitoring (Table 4$)$. WEl interval had an ascending trend for the winter-tosummer interval and a descending trend for the summer-to-winter interval. During the second year, the shortest WEI also occurred in winter and was again lower than in autumn $(P=0.026)$ and summer $(P$ $=0.003)$, but not in spring $(P=0.309)$. In all seasons, WEl decreased from the first to the second year $(P$ $<0.01$ ). The mean annual value of WEI was $15.94 \%$ lower in the second year than in the first year. $A$ combined statistical analysis of the first and second years revealed a difference in WEI between the two years of monitoring $(P=0.023)$.

Table 4 Weaning-to-oestrus interval (days) in different seasons in parity-1 sows in two consecutive years of climate adaptation

\begin{tabular}{|c|c|c|c|c|c|c|c|}
\hline \multirow{2}{*}{ Item } & \multicolumn{4}{|c|}{ Season $^{1}$} & \multirow{2}{*}{ Annual $^{1}$} & \multirow{2}{*}{ SD } & \multirow{2}{*}{$P$} \\
\hline & Autumn & Winter & Spring & Summer & & & \\
\hline First year of adaptation & $5.55^{\mathrm{b} ; \dagger} \pm 0.73$ & $5.22^{\dagger \dagger} \pm 0.73$ & $5.25^{\dagger} \pm 0.89$ & $6.06^{\mathrm{c} ; \dagger} \pm 0.65$ & $5.52^{\dagger} \pm 0.19$ & 0.58 & 0.046 \\
\hline Second year of adaptation & $4.96^{\mathrm{b} ; \ddagger} \pm 0.40$ & $4.28^{\mathrm{a}: \ddagger} \pm 0.50$ & $4.31^{\ddagger} \pm 0.30$ & $5.01^{c ; \ddagger} \pm 0.41$ & $4.64^{\ddagger} \pm 0.29$ & 0.38 & 0.020 \\
\hline
\end{tabular}

${ }^{1}$ Values are expressed as mean \pm SEM

${ }^{\mathrm{a}-\mathrm{c}}$ Row means with different superscripts differ significantly at $P<0.05$

†; $\ddagger$ Column means with different symbols differ significantly at $P<0.05$

\section{Discussion}

The time required for the gilts to adapt to a geographical and climate change resulted in increased variation of the age to first oestrus. A lower percentage of gilts reached oestrus within NPI limits, and the onset of puberty occurred at a greater age in the first year than in the second. The higher or lower ambient temperature of the season could exert a substantial effect on reproductive parameters and would also act as a stress factor (Prunier et al., 1996; Suriyasomboon et al., 2006; Einarsson et al., 2008). This was not the case for these gilts that were permanently situated within the limits of the neutral thermal zone during the two years of monitoring.

Previous reports have explained similar differences in reproductive performance based on photoperiod variations. Gilts and sows from temperate southern Norway compared with arctic/subarctic northern Norway showed differences in puberty age, number of piglets born and parturition rate (Gaustad-Aas et al., 2004). These data agree with those of Gaustad-Aas et al. (2004), which showed that these age differences in the onset of puberty are climatically programmed within certain limits. That is, the hastening of puberty appears to be caused by differences in regional photoperiodism (the main environmental factor that differentiates the two regions) rather than the ambient temperature differences (which were controlled mainly for the two locations).

Hutchens et al. (1978) identified seasonal differences of puberty in which gilts farrowed in spring were significantly younger (5.8 days) and significantly heavier at first oestrus than those that farrowed in autumn. A younger onset of puberty in spring and fewer gilts showing first oestrus in summer was identified by Peltoniemi et al. (2000) and Tummaruk et al. (2000).

Seasonal differences were demonstrated by Faillace et al. (1994) as a summer-autumn seasonal infertility, whereas the level of food consumption was shown to modify the age of first mating (Tummaruk et al., 2007). Seasonal differences in reproductive performance have been linked to seasonal photoperiodicity (Peltoniemi et al., 2000; Quesnel et al., 2005; Kraeling \& Webel, 2015).

Because the percentage of gilts with DE within the normal range increased and the variability decreased from year to year again, this signalled a stabilising effect of adaptation. Increased DE for all seasons in the second year could be interpreted as a positive result of a process of adaptation of the animals to the new climatic conditions. Changes in winter to spring and summer to autumn DE periods and maximum values obtained in autumn and the lowest in spring again suggest photoperiod-dependent effects. This finding is similar to several previous reports by Knox et al. (2002) and Kraeling \& Webel (2015).

Evaluating boar exposure on oestrus and ovulation in weaned sows, Knox et al. (2002) documented the existence of an increasing length of oestrus from January to April, a peak in April, and decreasing length in June and August. Furthermore, Kraeling \& Webel (2015) affirmed that the season influences the onset of oestrus, with the onset being later in summer than in late autumn and winter. Occurrence (or maintenance) 
of these changes during the two years of monitoring in the present experiment illustrates the existence of seasonal influences. Because photoperiodicity could explain the differences in puberty age and DE under different climatic conditions, this calls into question the involvement of the pineal-hypothalamus-pituitarygonad axis, but the specifics of this mechanism in pigs are far from being fully explained (Prunier et al., 1996; Tast, 2002; Chokoe \& Siebrits, 2009). It also calls for a controlled study that takes into consideration all factors of ambient temperature, melatonin, nutrition, and male effects, together with their interactions.

Another factor of DE influence is WEI itself: while WEI is under the influence of several factors, WEI itself decreases the DE, that is, a shorter WEI ( 3 to 4 days) induces a longer oestrus ( $\geq 6$ days) while a longer WEI induces a shorter oestrus (Kemp \& Soede, 1996).

Normally, WEI lasts from three to five days (Anderson, 1993, Kraeling \& Webel, 2015). A decrease of the annual mean and ranges of WEI during climate adaptation reveals that the adaptation process is positive, suggesting that the sows have adapted to the new climatic conditions. Taking into account the geographic region, an increase of WEI during the winter-summer interval and a subsequent decrease during the summer-to-winter interval could be caused by environmental photoperiodicity and temperature. According to Gaustad-Aas et al. (2004), a significantly lower proportion of sows from northern Norway $\left(65-71^{\circ} \mathrm{N}\right)$ were mated or inseminated within five days of post-weaning compared with those from southern Norway (59$60^{\circ} \mathrm{N}$ ), although environmental temperatures were within the neutral zone limits. Gourdine et al. (2006) noted that reproductive performance of Large White sows under tropical and humid climatic conditions in Guadeloupe $\left(16^{\circ} \mathrm{N}\right)$ had a mean WEI of 4.61 days in both hot and warm seasons. Knox et al. (2002) reported results for North America, with an average WEI of five days. Smaller decreases in WEI from the first year to the next are associated with summer and autumn and are recognized for their lower reproductive performance (Prunier et al., 1996; Kraeling \& Webel, 2015). WEI was also found to be slightly longer in summer, autumn, and winter than in spring (Knox \& Zas, 2001) and longer in June compared with February to April (Knox et al., 2002). Parity-1 sows are more susceptible to lower reproductive performance in summer with prolonged WEI and delayed puberty (Kraeling \& Webel, 2015). Koketsu \& Dial (1997) also observed that spring-parturition sows have longer WEI.

WEI has been reported to be affected by other factors such as parity (Knox \& Zas, 2001), climate seasonality (Gourdine et al., 2006), length of lactation (Mabry et al., 2006), and amount of feed intake (Knox \& Zas, 2001; Gourdine et al., 2006).

\section{Conclusions}

Gilts translocated between temperate climates from northern to southern Europe support a process of photoperiod-dependent climate adaptations of oestrus parameters. Seasonal effects on oestrus parameters, especially in winter, become more pronounced from the first year of adaptation to the second, in that puberty occurs earlier, WEI shortens, and DE becomes longer. The degree of variation decreases over the adaptation period for the age at which puberty occurs and DE. This results in a grouping effect for the gilts around the mean age of puberty and DE.

\section{Acknowledgements}

This research did not receive any specific grant from funding agencies in the public, commercial, or not-for-profit sectors. We wish to thank to Ruth Osborne, who kindly accepted to review the English version of the manuscript.

\section{Authors' contribution}

The contributions of the authors are as follows: ND conducted the research, analysed the results and wrote the paper. $C B, G C, I C$ and $S R$ participated in the animal experiment. RAB gave substantial contributions to the literature search, building the database, and writing the manuscript. All authors read and approved the final version of the article.

\section{Conflict of interest declaration}

The authors have no competing interests to declare.

\section{References}

Anderson, L.L., 1993. Pigs. In: Hafez, E.S.E. (editor). Reproduction in farm animals. 6th ed. Lea \& Febiger, Philadelphia, pp. 343-360.

Bernabucci, U., Lacetera, N., Baumgard, L. H., Rhoads, R.P., Ronchi B. \& Nardone, A. 2010. Metabolic and hormonal acclimation to heat stress in domesticated ruminants. Animal 4(7), 1167-1183.

Chokoe, T.C. \& Siebrits, F.K., 2009. Effects of season and regulated photoperiod on the reproductive performance of sows. S. Afr. J. Anim. Sci. 39, 45-54.

Einarsson, S., Brandt, Y., Lundeheim, N. \& Madej, A., 2008. Stress and its influence on reproduction in pigs: A review. Acta. Vet. Scand. 50, 48. Doi:10.1186/1751-0147-50-48.

Faillace, L.S., Biggs, C. \& Hunter, M.G., 1994. Factors Affecting The Age At Onset Of Puberty, Ovulation Rate And Time Of Ovulation In Chinese Meishan Gilts. J. Reprod. Fert. 100, 353-357. 
Gaustad-Aas, A.H., Hofmo, P.O. \& Karlberg, K., 2004. Reproductive performance of gilts and sows in temperate versus subarctic and arctic zones of Norway. Anim. Reprod. Sci. 80, 291-301. Doi:10.1016/j.anireprosci.2003.08.001.

Gourdine, J.L., Quesnel, H., Bidanel, J.P. \& Renaudeau, D., 2006. Effect of Season, Parity and Lactation on Reproductive Performance of Sows in a Tropical Humid Climate. Asian-Aust. J. Anim. Sci. 19, 1111-1119.

Hurtgen, J.P., Leman, D.A. \& Crabo, B., 1980. Seasonal influence on estrous activity in sows and gilts. J. Am. Vet. Med. Assoc. 176, 119-123.

Hutchens, L.K., Johnson, R.K., Welty, S.D. \& Schooley, J., 1978. Age and weight at puberty for purebred and crossbred gilts of four breeds. Animal Science Research Reports. Swine Research Report. Oklahoma Agricultural Research Station. http://beefextension.com/research reports/research 56 94/rr78/rr78 26.pdf (accessed 22.08.13).

Kemp, B.N. \& Soede, M., 1996. Relationship of weaning-to-oestrus interval to timing of ovulation and fertilization in sows. J. Anim. Sci. 74, 944-949.

Knox, R.V. \& Zas, S.L., 2001. Factors influencing oestrus and ovulation in weaned sows as determined by transrectal ultrasounds. J. Anim. Sci. 79, 2957-2963.

Knox, R.V., Willenburg, K., Miller, G. \& Rodriguez-Zas, S., 2002. Effect of frequency of boar exposure on oestrus and ovulation in weaned sows as determined by real-time ultrasound. 2002. http://livestocktrail.illinois.edu/ uploads/ porknet/ papers/ UISwinerep00.pdf 144-148. (accessed 09. 06.14).

Koketsu, Y. \& Dial, G.D., 1997. Factors influencing the postweaning reproductive performance of sows on commercial farms. Theriogenology. 47, 1445-1461.

Kraeling, R.R. \& Webel, S.K., 2015. Current strategies for reproductive management of gilts and sows in North America. J. Anim. Sci. Biotechnol. 6, 41-69. Doi:10.1186/2049-1891-6-3.

Mabry, J.W., Culbertson, M.S. \& Reeves, D., 2006. Effects of lactation length on weaning-to-first service interval, firstservice parturition rate, and subsequent litter size. J. Swine Health Prod. 4, 185-188.

Peltoniemi, O.A.T.,Tast, A. \& Love, J.R., 2000. Factors effecting reproduction in the pig: seasonal effects and restricted feeding of the pregnant gilt and sow. Anim. Reprod. Sci. 60-61, 173-184.

Prunier, A., Messias de Bragança, M. \& Le Dividich, J., 1996. Influence of high ambient temperature on performance of reproductive sows. Livest. Prod. Sci. 52:123-133. Doi:10.1016/S0301-6226(97)00137-1.

Quesnel, H., Boulot, S. \& Le Cozler, Y., 2005. Seasonal variation of reproductive performance of the sow. I.N.R.A. Prod. Anim. 8, 101-110.

SAS, 2002. Statistical Analysis Systems user's guide (version 9.1.3.). SAS Institute Inc., Raleigh, North Carolina, USA.

Somade, B. \& Makinde, A.O., 1985. The influence of season on sow weaning to oestrus interval and subsequent reproductive performance following oestrus synchronization by batch weaning. Beitr. Trop. Landwirtsch. Veterinarmed. 23, 339-343.

Suriyasomboon, A., Lundeheim, N., Kunavongkrit, A. \& Einarsson, S., 2006. Effect of temperature and humidity on reproductive performance of crossbred sows in Thailand. Theriogenology. 65, 606-628. Doi:10.1016/j.theriogenology.2005.06.005.

Tast, A., 2002. Endocrinological basis of seasonal infertility in pigs. http://ethesis.helsinki.fi/ julkaisut/ela/ kliin/ vk/ tast/ endocrin.pdf (2002) (accessed 01.06.13).

Tummaruk, P., Lundeheim, N., Einarsson, S. \& Dalin, A.M., 2000. Factors influencing age at first mating in purebred Swedish Landrace and Swedish Yorkshire gilts. Anim. Reprod. Sci. 63, 241-253.

Tummaruk, P., Tantasuparuk, W., Techakumphu, M. \& Kunovongkrit, A., 2004. Effect of season and outdoor climate on litter size at birth in purebred Landrace and Yorkshire sows in Thailand. J. Vet. Med. Sci. 66, 477-482.

Tummaruk, P., Tantasuparuk, W., Techakumphu, M. \& Kunavongkrit, A., 2007. Age, body weight and backfat thickness at first observed ooestrus in crossbred Landrace $\times$ Yorkshire gilts, seasonal variations and their influence on subsequence reproductive performance. Anim. Reprod. Sci. 99, 167-181.Doi:10.1016/j.anireprosci.2006.05.004. 